\title{
Development of Digital Repository and Retrieval System for Rose Germplasm Management
}

\author{
Radhika V* and Tejaswini ${ }^{1}$ \\ ${ }^{1}$ Division of Floriculture and Medicinal Crops \\ Division of Plant Genetic Resources, ICAR-Indian Institute of Horticultural Research \\ Hesaraghatta Lake PO, Bangalore - 560089, Karnataka, India \\ *Email : Radhika.V@icar.gov.in
}

\begin{abstract}
Live repository of rose consisting of different genotypes and species of roses available across the globe has been established at ICAR-IIHR. All these genotypes have been characterized for 60 morphological characters for description of these varieties. Along with the live repository of plants, efforts have been made to develop digital repository of all these genotypes. The digital repository consists of description of characters, quantitative measurement for selected important characters and images for all the descriptors. A web-enabled interface has been developed for the selective retrieval of accessions with desired characters, and also for retrieval of all the information for the selected genotype. The information system will be useful across the germplasm collection centers, for the breeders and other end users by enabling them to select the appropriate germplasm and avoid duplicates.
\end{abstract}

Keywords: Rose, germplasm, digital repository, database, information system

\section{INTRODUCTION}

The conservation and utilization of genetic diversity is important for the present use and for the future needs for sustainable utilization and development (Rao and Hodgkin 2002). Any breeding program is based on the availability of genetic resources in the species and also encompasses the related species and general. The number of genotypes in any germplasm collection and live repository is limited by the space, labour and the enormous fund required for management of the genetic resource. With the concentrated efforts of breeding programs happening around the globe, hundreds of varieties are added every year in most of the species and practically it becomes difficult to hold all the germplasm at one location. Breeders and researchers face the difficulty of locating specific types of genetic diversity for the breeding programmes. It is often difficult to find information about accessions which have certain traits of interest like higher yield, resistance to biotic or abiotic stresses etc. Hence, documentation and cataloguing of the germplasm information is necessary to properly conserve and utilize the germplasm.
Mining the germplasm information is also necessary for understanding the crop diversity and for its effective utilization for sustaining abundant production and a healthy environment (Arnaud et al., 2010).

With the recent developments and issues being raised on the international platform, exchange of genetic material is becoming extremely cumbersome. On the contrary digital world is expanding, breaking all the barriers of political and geographical boundaries. In this era of information technology, the need of the hour is to build an information system for retrieval of all information related to the germplasm of a species. As a prelude, web based information system for rose, a crop of international and commercial importance was chosen because of availability of information. With the importance being laid on enhancing farmers' income and to earn from export, rose cultivation is gaining importance and popularity among the farmers with the help of government subsidized programs. Rose is popularly known as the queen of flowers and an integrated part of garden and landscape. Rose has nearly 200 species most of that originated from temperate region and few of tropical 
origin (Fougere-Danezanet al, 2014). Though rose fragrance is highly appreciated, all roses are not fragrant and the fragrant roses are sought after by the aromatic, perfume and cosmetic industries. Roses are cultivated for cut flowers with long stalk as well as loose flowers with simple pedicel. Rose is a crop of low volume and high price and farmers cultivate it as commercial crop for both domestic and export market.

The ICAR - Indian Institute of Horticultural Research (ICAR-IIHR) has been involved for quite a long time in the collection, conservation and improvement of germplasm of major horticultural crops for the past five decades. This study was taken up with two major objectives (i) to build digital repository of the rose genotypes and (ii) to develop web-enabled interface to retrieve essential information on rose and its desired genotypes.

Numerous germplasm databases have been developed by various researchers namely, Horry et al (2002) in pineapple; Rajagopal et al (2005) in coconut; Upadhyaya et al (2007) in pearl millet; Savita and Hussain (2009) in soybean; Singh et al (2013) in banana; Praveen et al (2015) in sugarcane.

\section{MATERIALS AND METHODS}

ICAR-IIHR is located at Hesaraghatta, Bangalore $\left(13^{\circ} 08^{\prime} \mathrm{N}, 7^{\circ} 29^{\prime} \mathrm{E}, 767 \mathrm{~m}\right.$ above sea level). The weather is moderate and the soil is of red type. Rose germplasm collection at ICAR-IIHR consists of 320 genotypes classified under different categories. The collection comprises of indigenous as well as exotic varieties and most of them belong to Rosa hybrid. It includes horticultural categories of Hybrid Tea, Floribunda, ramblers as well as climbers. At ICARIIHR 13 different species of rose are being maintained. In this study model, the genotypes was classified based on utility (fragrant, cut flowers and loose flowers of spray type) focusing on genetic improvement for farmers' needs.

The characterisation descriptors for the germplasm collection are based on the 60 descriptors as laid down by the Protection of Plant Varieties \& Farmers Rights Authority (PPV\&FRA), Government of India, in the Guidelines for the Conduct of Test for Distinct, Uniformity and Stability (DUS) on rose for establishment of uniqueness of a genotype (Table 1). The descriptor consists of 17 vegetative and 43 reproductive characters. Among the vegetative characters, 9 are leaf and 8 are stem characters, while 41 floral and 2 fruit characters included describe the reproductive characters. Germplasm collection is authenticated by its passport data hence; we have included the same in our information system. Every character has a list of states explained in words and each state is represented by an integer code (Table 1)

The information system was developed in WampServer 2.5 web hosting platform on Windows operating system. The backend database has been developed in MySQL relational database management system (RDBMS) and it consists of 62 tables - one for passport data, one for characterization data and remaining for the various other characters. The descriptor and passport data was collected in Excel files and imported into the database using phpMyAdmin administration tool. The web-based user interface for the database was developed in Hypertext Markup Language (HTML) and Hypertext Preprocessor (PHP) languages. PHP's mysqli extension application programming interface (API) has been selected for interacting with the MySQL database server. The variables are passed between the search and result pages using the POST method.

\section{RESULTS AND DISCUSSION}

A digital repository, which facilitates easy accessibility of the information about the conserved rose germplasm, which in turn facilitates utilization of the resources, was presented. It comprises of a relational database in MySQL for storing the rose germplasm characterization data and a web enabled user interface. The database comprises of 62 tables. The "Passport" table consists of the passport data for the varieties. The second table "Character" consists of the 60 characters for all the varieties, the characters being in the form of coded values as given in the DUS characterization guidelines (Table 1). The remaining 60 tables consist of the values of the codes for each character. The descriptor and passport data was initially tabulated in Excel files and later imported into the respective tables of the database from phpMyAdmin interface. All the database management operations were performed through the phpMyAdmin interface. 
A web based interface has been developed for facilitating information retrieval (Fig 1). The data entry form (Fig 2) enables the user to select the character options from drop down menu and submit to the database. The data edit form facilitates the users to select a variety for editing and is presented with the various character options of the variety (Fig 3) for updating the database. The search menu (Fig 4a) consists of drop down menus-one for each character. The options for one / more character can be selected from the corresponding drop down menu and submitted by clicking the "Submit" button. The accessions having the selected characters will be depicted in a table which can be exported to an Excel file (Fig 4b). On clicking the name of any accession, the accession details along with a small image for each character can be viewed in a new web page (Fig 4c). Upon clicking the small image, a new tab opens with a bigger version of the same image. For any given character, the different categories of a character can be obtained in the form of a dynamic pie chart (Fig 5). Fig 5 depicts the pie chart for the various categories of plant growth type and the percentages are also given. The upload image page enables the user to select a variety and upload images for all the characters of that variety (Fig 6).

The rose germplasm repository has been made available on the intranet of IIHR for the Scientists' suggestions and their inputs have been considered for further development. The repository is being regularly updated with the latest data and images. The system provides a means for storing the wealth of accession information and images in a single place. It serves as a ready-reckoner for viewing the required information/ images in a short span of time with a few mouseclicks. It also facilitates the comparison of germplasm with respect to distinct/ similar characters.

Germplasm databases developed for few agricultural crops have been reviewed and discussed. The ICRISAT Data Management and Retrieval System (IDMRS) was developed at ICRISAT to manage the passport, characterization, inventory and distribution data of pearl millet (Upadhyaya et al., 2007). Sugarcane Germplasm Database (SGDB) has been developed for 45 descriptors (which includes 27 DUS descriptors as described in PPV\&FRA, India and 18 agronomic and quality descriptors) of 131 germplasm accessions of sugarcane (Praveen et al., 2015). The CIRAD pineapple germplasm database hosts data of over 600 pineapple accessions which includes the origin, botanical description and agronomic behavior of the accessions; the documentation being based on IPGRI plant descriptors (Horry et al., 2002). Germplasm database based on phenotypic descriptors and SSR molecular markers analysis has been developed for the plum germplasm resources in Romania (Harta et al., 2016). A database comprising of 28 genotypes of Musaceaehas been developed for the banana resources of Manipur (Singh et al., 2013). This database provides access to the details of taxonomy, morphological characters, utility and sites of collection of Musa genotypes. An online soybean information system facilitates information retrieval from 2000 germplasm accessions of soybean (Savita and Husain, 2009). A coconut germplasm database comprising of evaluation and characterization data has been developed and the information is available in the Coconut Genetic Resources Database (Rajagopal et al., 2005). The developed digital repository is the first of its kind in ICAR-IIHR with regard to rose. Images were included for all rose varieties which is very useful since a user can have access to detailed images and this will be more helpful in decision making while choosing the accessions for further selection and multiplication

\section{CONCLUSION}

Digital repository for the passport and characterization data of the rose germplasm collection available at ICAR-IIHR was developed. The repository has proved to be a valuable tool for the breeders for effective utilization of germplasm for further breeding programmes. This system can be customized for digitization of any other crop characterization data. Efforts are on to expand the digital repository with more varietal information. The digital repository is expected to be used as a global platform for management of Rose germplasm information.

\section{ACKNOWLEDGEMENT}

The authors are grateful to PPV\&FRA for providing funds for carrying out the work. The authors are also thankful to the Director, ICARIIHR for providing the facilities required for this study. 
Table 1. List of DUS descriptors for rose

\begin{tabular}{|c|c|c|}
\hline No. & Character & Character States and Codes \\
\hline 1 & Plant: growth type & $\begin{array}{l}\text { Ground cover (1); Miniature (2); Dwarf (3); Bed (4); } \\
\text { Shrub (5); Climb (6) }\end{array}$ \\
\hline 2 & $\begin{array}{l}\text { Plant growth habit (Excluding varieties with } \\
\text { growth type climber) }\end{array}$ & $\begin{array}{l}\text { Upright (1); Semi-upright (3); Intermediate (5); } \\
\text { Moderately spreading (7); Strongly spreading (9) }\end{array}$ \\
\hline 3 & Plant: height (during second flush) & $\begin{array}{l}\text { Very short }(<30)(1) \text {; Short }(<60)(3) \text {; } \\
\text { Medium }(60-100)(5) \text {; Tall }(>100)(7) \text {; Very tall }(>100)(9)\end{array}$ \\
\hline 4 & Young shoot: anthocyanin colouration & Absent (1); Present (9) \\
\hline 5 & Young shoot: Intensity of anthocyanin colouration & $\begin{array}{l}\text { Very weak (1); Weak (3); Medium (5); Strong (7); } \\
\text { Very strong (9) }\end{array}$ \\
\hline 6 & $\begin{array}{l}\text { Stem: Number of prickles } \\
\text { (excluding very small and hairy like prickles) }\end{array}$ & Absent (1); Few (3); Medium (5); Many (7) \\
\hline 7 & Prickles: Predominant colour (as for 6) & $\begin{array}{l}\text { Greenish (1); Yellowish (2); Reddish (3); Brown (4); } \\
\text { Purplish (5) }\end{array}$ \\
\hline 8 & Prickles:shape of Lower side & $\begin{array}{l}\text { Deep concave (1); Concave (3); Flat (5); Convex (7); } \\
\text { High convex (9) }\end{array}$ \\
\hline 9 & Leaf: size & Small (1); Medium (3); Large (5) \\
\hline 10 & $\begin{array}{l}\text { Leaf: Intensity of green colour on upperside } \\
\text { (at the time of first flowering) }\end{array}$ & $\begin{array}{l}\text { Very light (1); Light (3); Medium (5); Dark (7); } \\
\text { Very dark (9) }\end{array}$ \\
\hline 11 & Leaf: Anthocyanin colouration & Absent (1); Present (9) \\
\hline 12 & Leaf: glossiness of upper side & Absent (1); Weak (3); Medium (5); Strong (7) \\
\hline 13 & Leaflet: Undulations of margin & Absent (1); Weak (3); Medium (5); Strong (7) \\
\hline 14 & Leaflet: Serration of the margin & Absent (1); Fine (3); Medium (5); Dense (7) \\
\hline 15 & Terminal leaflet: Shape of blade & $\begin{array}{l}\text { Narrow elliptic (1); Medium elliptic (2); } \\
\text { Ovate (3); Circular (4) }\end{array}$ \\
\hline 16 & Terminal leaflet: shape of the base of blade & Acute (1); Obtuse (3); Rounded (5); Cordate (7) \\
\hline 17 & Terminal leaflet: Shape of apex of blade & Acuminate (1); Acute (2); Obtuse (3); Rounded (4) \\
\hline 18 & Flowering shoot: flowering laterals & Absent (1); Present (9) \\
\hline 19 & Flowering shoot: number of flowering laterals & Few (1); Medium (3); Many (5) \\
\hline 20 & $\begin{array}{l}\text { Flowering shoot: number of flowers } \\
\text { (for varieties with no flowering laterals) }\end{array}$ & Few (1); Medium (3); Many (5) \\
\hline 21 & $\begin{array}{l}\text { Flowering Shoot: number of flowers per lateral } \\
\text { (for varieties with flowering laterals }\end{array}$ & Few (1); Medium (3); Many (5); \\
\hline 22 & $\begin{array}{l}\text { Flower bud: shape of longitudinal section } \\
\text { (just before separation of sepals) }\end{array}$ & Elliptic (1); round (2); Ovate (3); Broad ovate (4) \\
\hline
\end{tabular}


23 Flower: type

24 Flower no of petals

Flower: color group

26

Flower: diameter (cm)

Flower: color of the center

28

29

30

(fully opened flower)

31 Flower: side view of lower part (fully opened flower)

Sepal: extensions

35

37

38

39

40

Petal: width

41

Petal: number of colors on inner side (basal spot excluded)

42 Varieties with one color on inner side of petal: intensity of color excluding the basal spot
Single (1); Semi-double (2); Double (3)

Few (<20) (1); Medium (20-30) (3); Many (>30) (5)

White or near white (1); White blend (2); Green (3);

Yellow (4); Yellow blend (5); Orange (6);

Orange blend (7); Pink (8); Pink blend (9); Red (10);

Red blend (11); Red purple (12); Purple (13);

violet blend (14); Brown blend (15); Multicoloured (16);

Pink blend (17); Mauve (18); Apricot blend (19)

Small (4.0-6.0) (1); Medium (6.1-8.0) (3);

Large (8.1-10.0) (5)

Green (1); Yellow (2); Orange (3); Pink (4);

Red (5); Purple (6); White (7)

Very loose (1); Loose (3); Medium (5); Dense (7)

Round (1); Irregulary round (2); Star shaped (3)

Flat (1); Flattened convex (2); Convex (3)

Concave (1); Flat (2); Flattened convex (3); Convex (4)

Absent (1); Weak (3); Medium (5); Strong (7)

Absent (1); Few (3); Medium (5); Many (7)

Absent (1); Present (9)

Elliptic (1); Obovate (2); Rounded (3)

Absent (1); Weak (3); Medium (5); Strong (7)

Absent (1); Weak (3); Medium (5); Strong (7)

Absent (1); Weak (3); Medium (5); Strong (7)

Very short (1); Short (3); Medium (5); Long (7);

Very long (9)

Very narrow (1); Narrow (3); Medium (5);

Broad (7); Very broad (9)

One (single) (1); Two (double) (2);

More than two (multiple) (3)

Lighter towards the base (1); Uniform (2);

Lighter towards the top (3)

43 Petal: Colour of the majority portion of the petal

$44 \quad$ Varieties with two or more colors

on inner side of petal: secondary color

(basal spot excluded) 
$45 \quad$ Varieties with two or more colours on inner side of petal: Tertiary colour of petal (basal spot excluded )

$46 \quad$ Varieties with two or more colours on inner side of petal: Petal distribution of secondary colour on inner side (basal spot excluded )

$47 \quad$ Varieties with two or more colours on inner side of petal: Petal distribution oftertiary colour on inner side (basal spot excluded )

48 Petal: spot at base of inner side

49 Petal: size of spot at base of inner side

50 Petal: colour of spot at base of inner side

51 Petal: colour of spot at base of outer side

52 Petal: main color on the outer side (only if clearly different from inner side)

53 Petal: spot at base of outer side

54 Petal: size of spot at base of outer side

55 Outer Stamen: Predominant Color of filament

56 Seed vessel: size (at petal fall)

57 Hip: shape of longitudinal section

58 Hip: color (at mature stage, for varieties grown for hip only)

59 Flower: length of pedicle

60 Flower: venation of petals
At base (1); at apex (2); At marginal zone (3); As a flush (); As a segment or stripes (5); As speckles (6)

At base (1); at apex (2); At marginal zone (3); As a flush (4); As a segment or stripe (5); As speckles (6)

Absent (1); Present (9)

Small (3); Medium (5); Large (7)

Small (3); Medium (5); Large (7)

White (1); Green (2); Light yellow (3);

Medium yellow (4); Orange (5); Pink (6); Red (7);

Brown red (8); Purple (9)

Very small (1); Small (3); Medium (5); Large (7);

Very large (9)

Funnel shaped (1); Pitcher shaped (2); Pear shaped (3)

Short (3); Medium (5); Long (7)

Absent (1); Weak (3); Medium (5); Strong (7) 


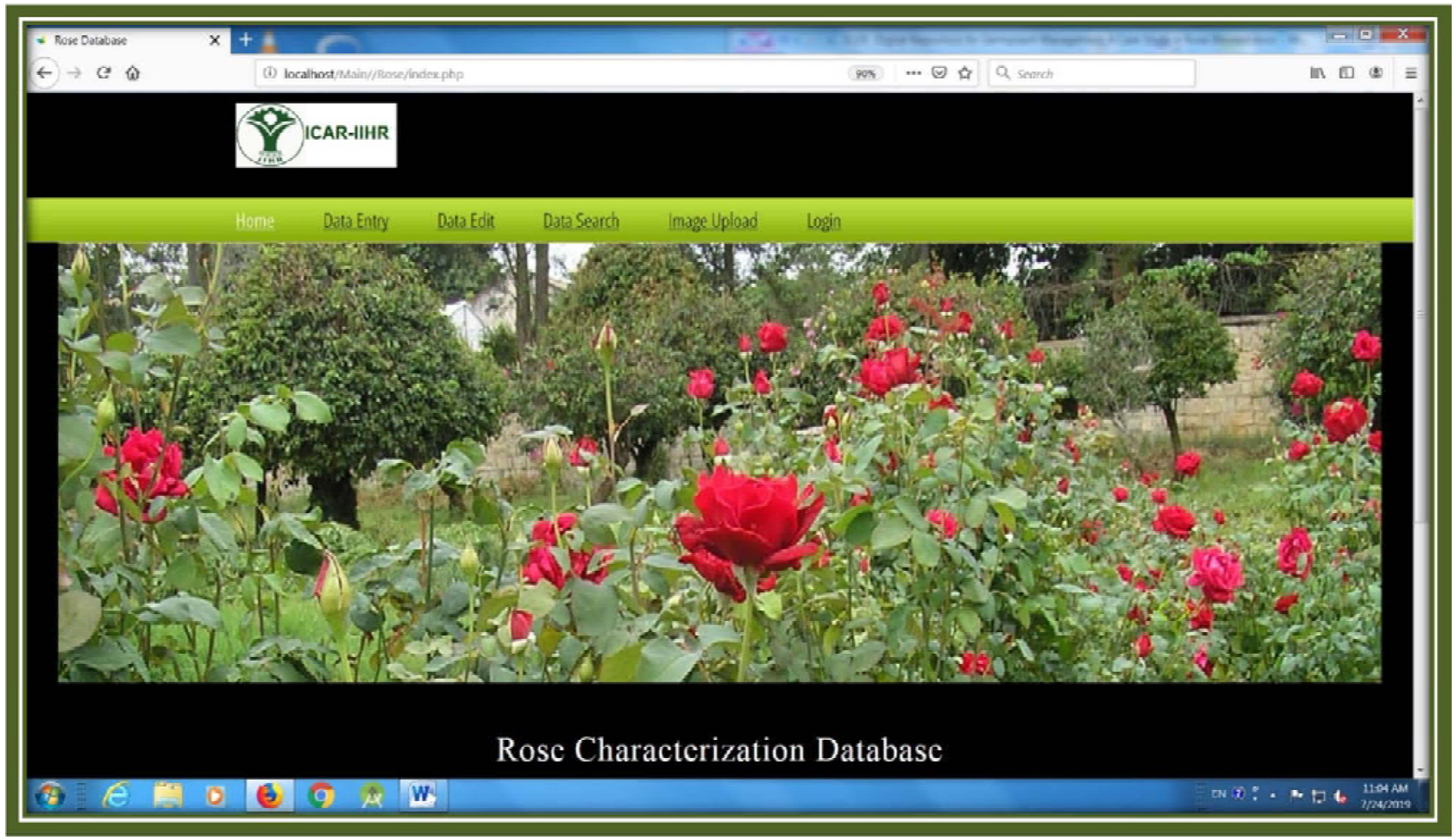

Fig. 1. Main page of the web interface

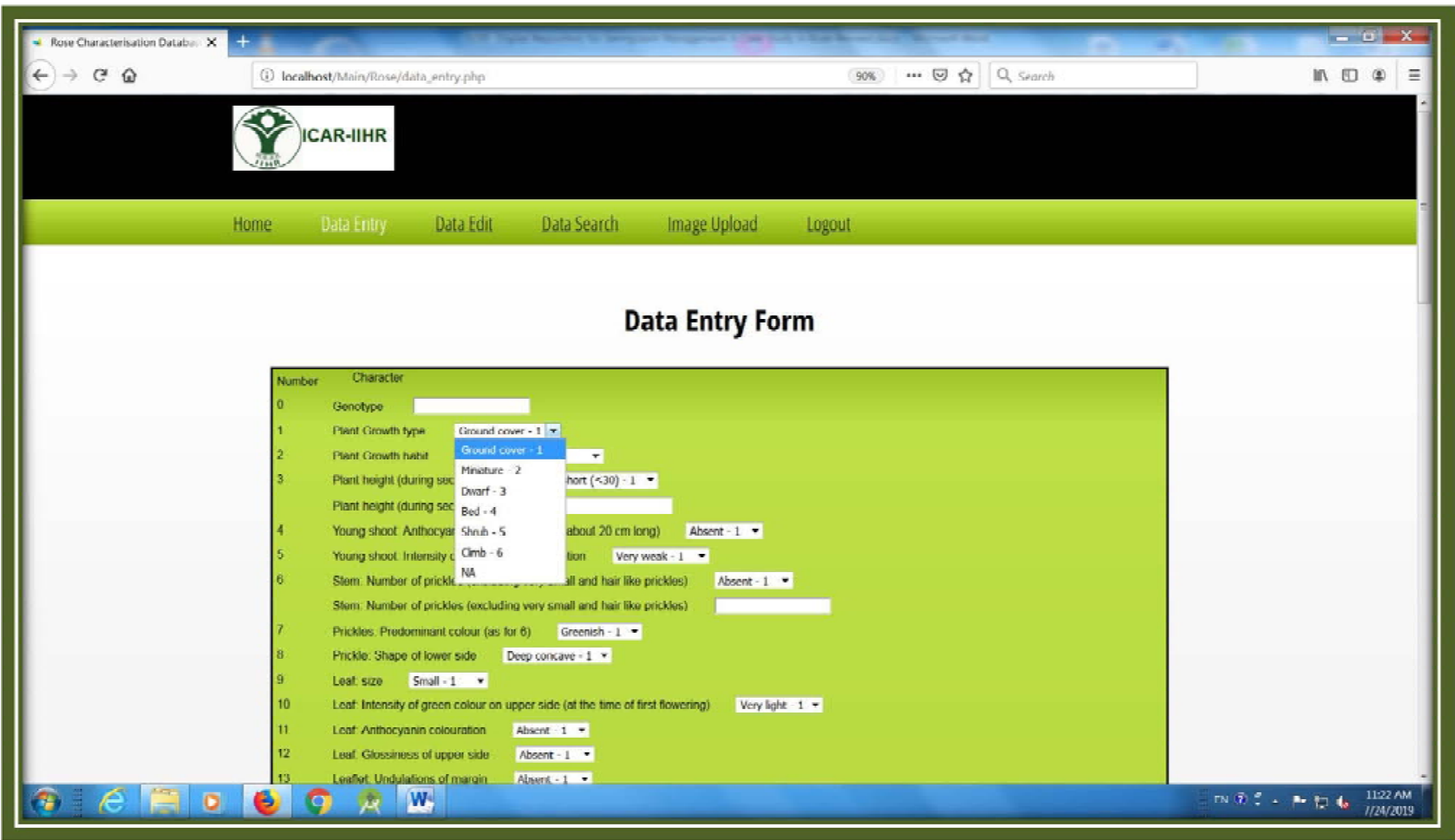

Fig..2.Data entry form 


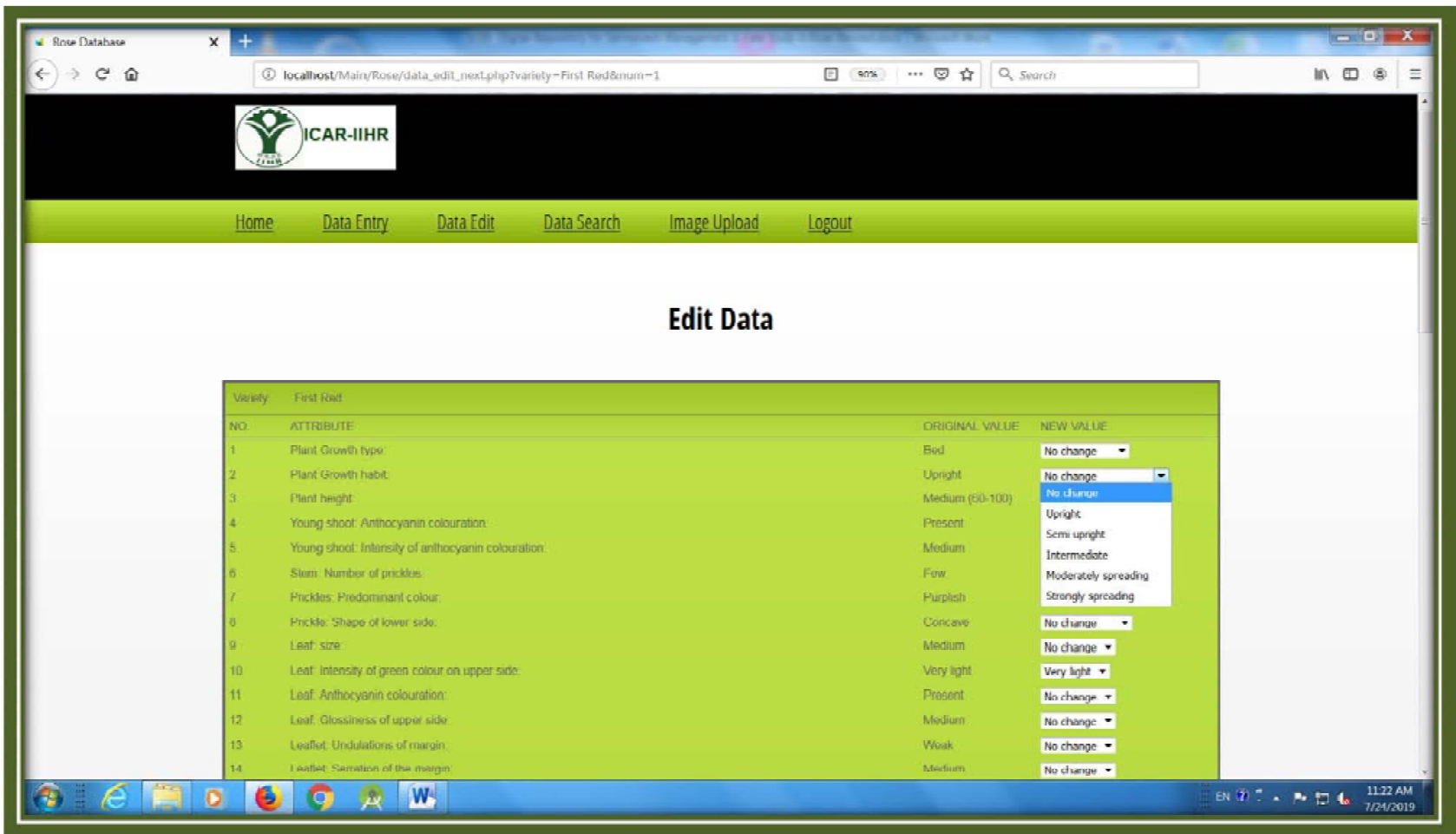

Fig. 3. Data editing page for a variety

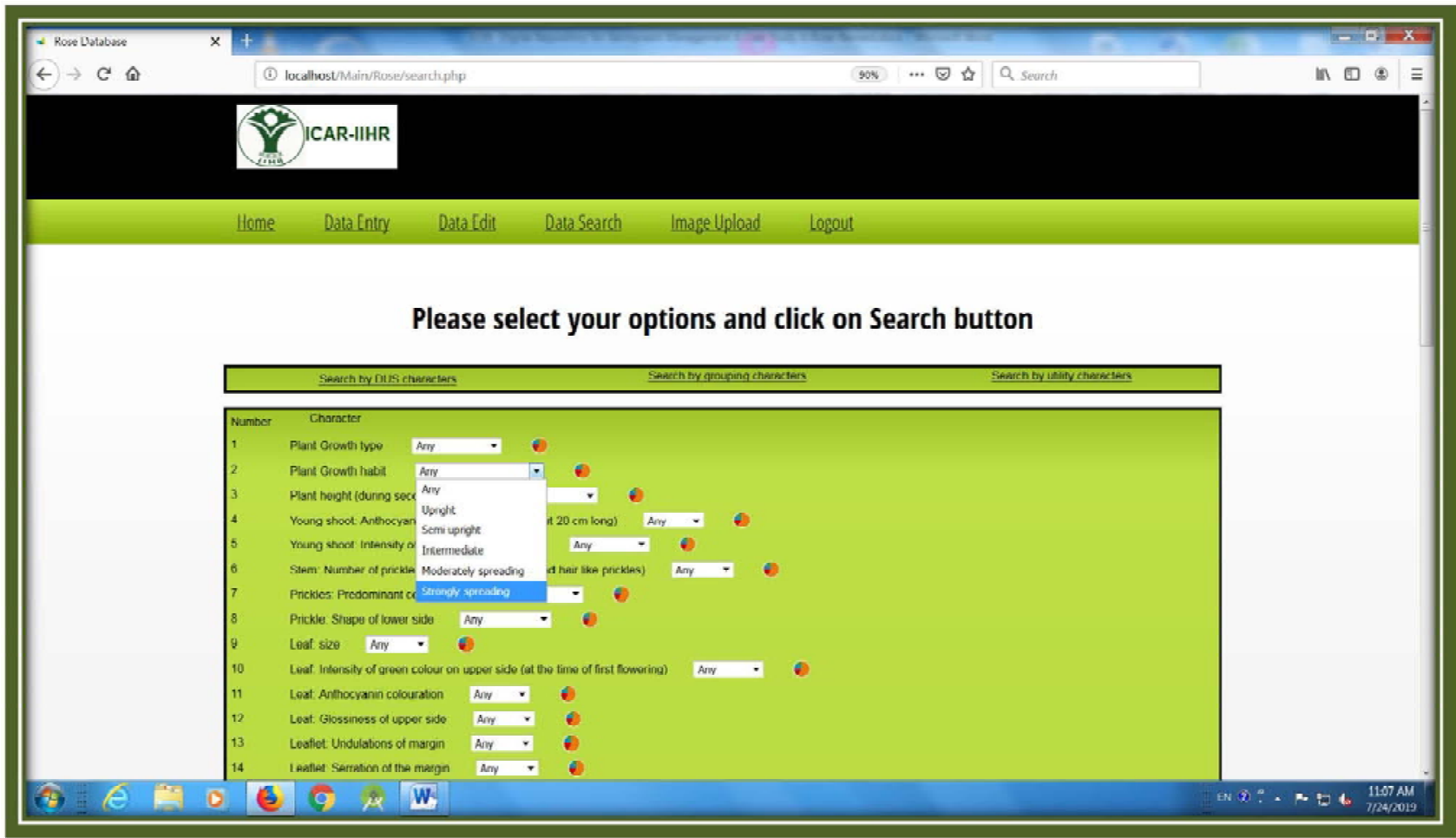

Fig. 4 (a). Data search page 


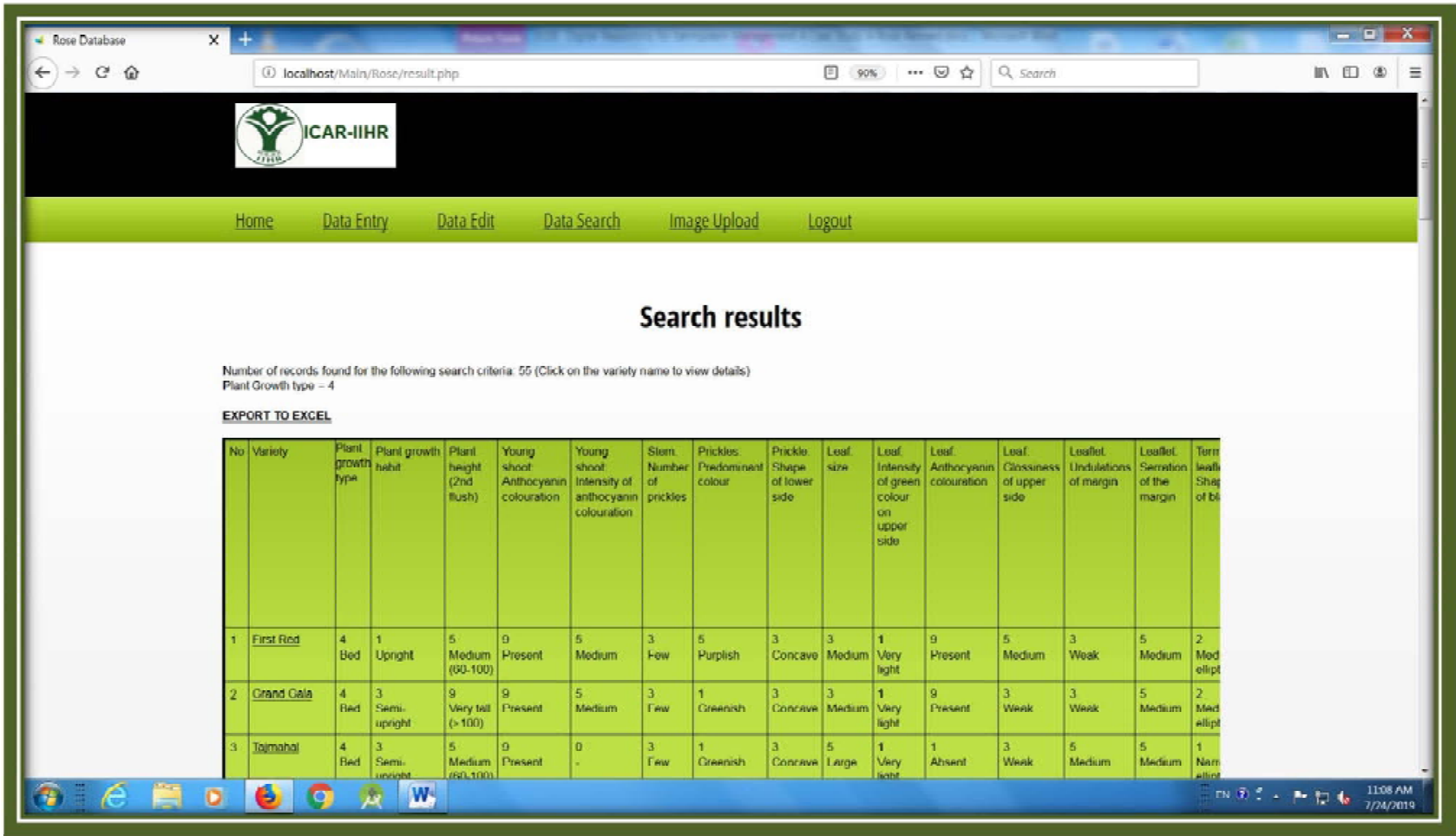

Fig. 4 (b). Search results

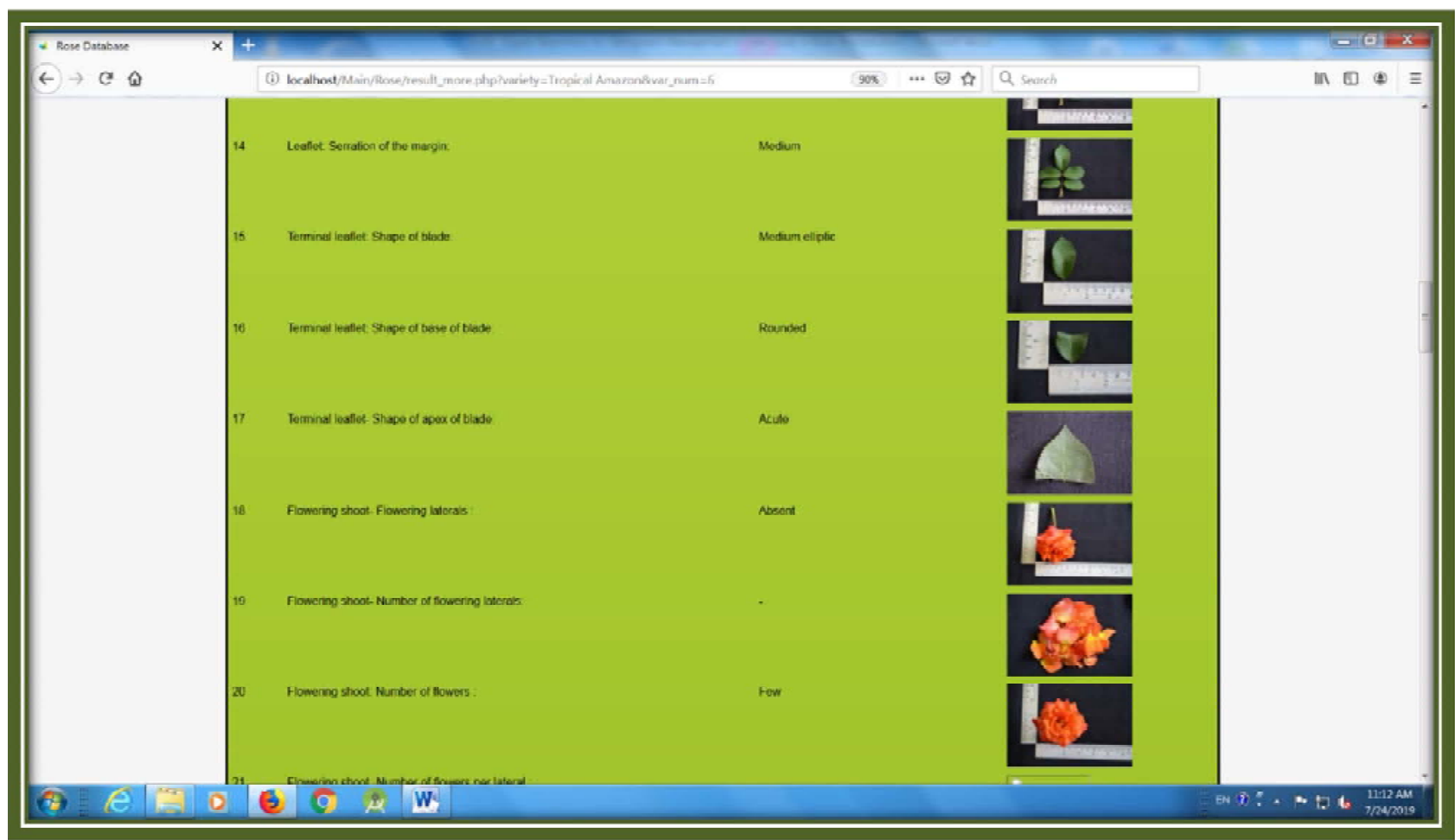

Fig. 4(c). Individual accession details with images 


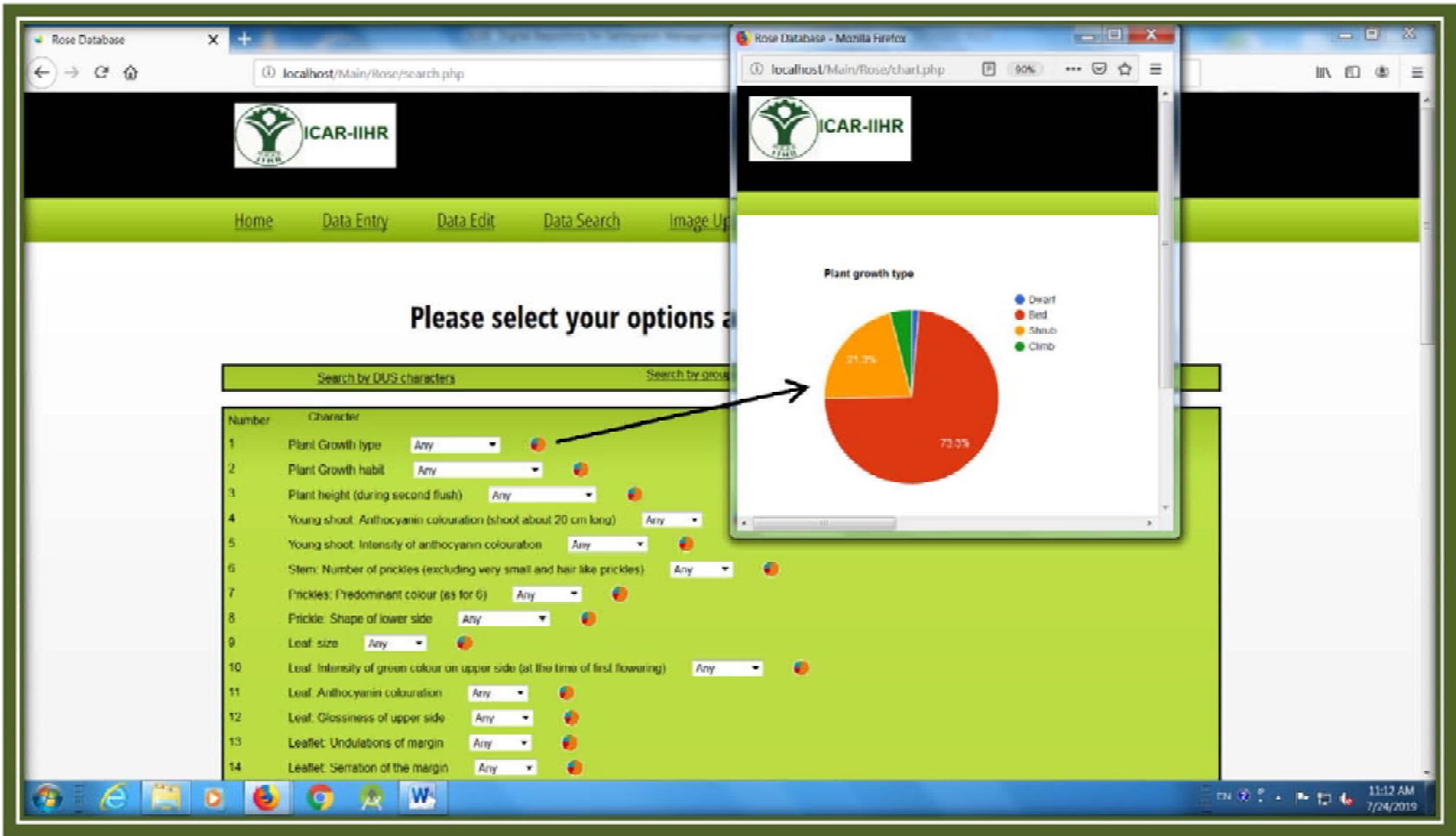

Fig. 5. Frequency chart for the diferent types of a character

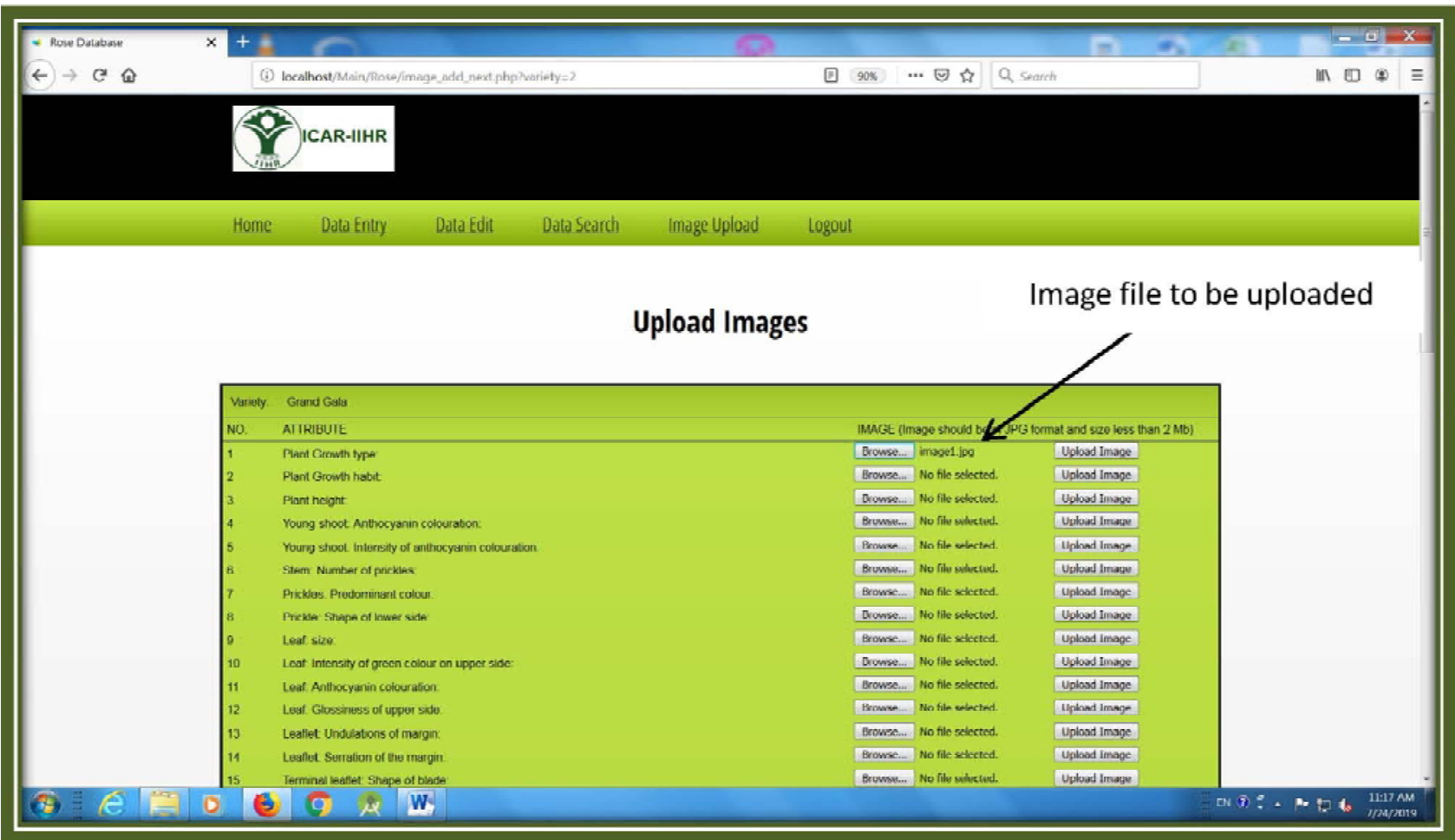

Fig. 6. Image upload page for a variety 


\section{REFERENCES}

Arnaud, E., Dias, S., Mackay, M., Cyr, P.D., Gardner, C.A., Bretting, P.K., Kinard, G.R., Guarino, L. and Louafi, S. 2010. A global portal enabling worldwide access to information on conservation and use of biodiversity for food and agriculture. In: Information and Communication Technologies for Biodiversity Conservation and Agriculture, Shaker Verlag, Aachen, Germany, pp. 168-180.

Fougere-Danezan, M., Joly, S., Bruneau, A., Gao, X. F., and Zhang, L. B. (2014). Phylogeny and biogeography of wild roses with specific attention to polyploids. Ann. Botany. 115(2):275-291.

Harta, M., Sisea, C.R., Pop, R., Szabo, K., Zănescu, M., Clapa, D. and Pamfil, D. 2016. The Current Status of Germplum Database: a Tool for Characterization of Plum Genetic Resources in Romania. Bull. UASVM Hort.73(2):240-241.

Horry, J.P., Lenoir, H., Perrier, X. and Teisson, C. 2002. The CIRAD pineapple germplasm database. In: Proc. of 4th Intel. Pineapple Symp. 16-19 April 2002. Mexico,pp. 73-6.

Praveen, K., Kumar, M.H., Umamaheshwari, A., Reddy, D.M., Sudhakar, P., Munikumar, M.,
Pradhan, D. and Sabita, N. 2015. SGDB: A Sugarcane Germplasm Database. Sugar Tech.17(2):150-155.

Rajagopal, V., Manimekalai, R., Krishnamurthy Devakumar, R., Karun, A., Niral, V., Gopal, M., Aziz, S., Gunasekaran, M., Kumar, M.R. and Chandrasekar, A. 2005. A database for coconut crop improvement. Bioinformation. 1(2):75.

Rao, V.R. and Hodgkin, T. 2002. Genetic diversity and conservation and utilization of plant genetic resources, Plant Cell Tiss. Org.68 (1):1-19.

Savita, K., and Husain, S.M. 2009. On-line Soybean Germplasm Information System. Soybean Res.7:82-88.

Singh, W.A., Gopalrao, S.B., Gourshyam, T., Handique, P.J. and Devi, H.S. 2013. DEBDOM: Database exploring banana diversity of Manipur. Bioinformation.9(5):270273.

Upadhyaya, H.D, Reddy, K.N. and Gowda, C.L.L. 2007. Pearl millet germplasm at ICRISAT genebank-status and impact. J. SAT Agric. Res.3:5pp.

(MS Received 24 May 2019, Revised 24 June 2019, Accepted 30 June 2019) 